LA W RENCE LIVERMORE NATIONAL LABORATORY

\section{Mechanical Characterization of Nodular Ductile Iron}

H. K. Springer

January 5, 2012 
This document was prepared as an account of work sponsored by an agency of the United States government. Neither the United States government nor Lawrence Livermore National Security, LLC, nor any of their employees makes any warranty, expressed or implied, or assumes any legal liability or responsibility for the accuracy, completeness, or usefulness of any information, apparatus, product, or process disclosed, or represents that its use would not infringe privately owned rights. Reference herein to any specific commercial product, process, or service by trade name, trademark, manufacturer, or otherwise does not necessarily constitute or imply its endorsement, recommendation, or favoring by the United States government or Lawrence Livermore National Security, LLC. The views and opinions of authors expressed herein do not necessarily state or reflect those of the United States government or Lawrence Livermore National Security, LLC, and shall not be used for advertising or product endorsement purposes.

This work performed under the auspices of the U.S. Department of Energy by Lawrence Livermore National Laboratory under Contract DE-AC52-07NA27344. 


\title{
Mechanical Characterization of Nodular Ductile Iron
}

\author{
H. K. Springer
}

\section{Summary}

The objective of this study is to characterize the strength and fracture response of nodular ductile iron (NDI) and its underlying ferritic matrix phase. Quasistatic and split Hopkinson pressure bar (SHPB) compression tests were performed on NDI and a model material for the NDI matrix phase (Fe-Si alloy). Smooth and notch round bar (NRB) samples were loaded in tension until fracture to determine strain-at-failure with varying stress triaxiality. Multiple tests were performed on each small and large smooth bar samples to obtain fracture statistics with sample size. Fracture statistics are important for initializing simulations of fragmentation events. Johnson-Cook strength models were developed for the NDI and the Fe-Si alloy. NDI strength model parameters are: $A=525 \mathrm{MPa}, B=650 \mathrm{MPa}$, $n=0.6$, and $C=0.0205$. The average SHPB experimental strain-rate of $2312 / \mathrm{s}$ was used for the reference strain-rate in this model. Fe-Si alloy strength model parameters are: $A=560$ $\mathrm{MPa}, B=625 \mathrm{MPa}, n=0.5$, and $C=0.02$. The average SHPB experimental strain-rate of $2850 / \mathrm{s}$ was used for the reference strain-rate in this model. A Johnson-Cook failure model was developed for NDI with model parameters: $D_{1}=0.029, D_{2}=0.44, D_{3}=-1.5$, and $D_{4}=D_{5}=0$. An exponential relationship was developed for the elongation-at-failure statistics as a function of length-scale with model parameters: $S_{f 1}=0.108, S_{f 2}=-0.00169$, and $L_{m}=32.4 \mu \mathrm{m}$. NDI strength and failure models, including failure statistics, will be used in continuum-scale simulations of explosively-driven ring fragmentation. The Fe-Si alloy strength model will be used in mesoscale simulations of spall fracture in NDI, where the NDI matrix phase is captured explicitly. 


\section{Methods}

\section{Materials}

Nodular ductile iron (NDI) is a Fe-C-Si alloy and its chemical composition by weight is 93.3\% Fe, 3.7\% C, 2.5\% Si, 0.3\% Mn. NDI also has trace amounts of $\mathrm{P}, \mathrm{S}, \mathrm{Cr}$, and Mg. NDI comprises a ductile matrix (first phase) with loosely-bound, graphite particles (secondphase) that are central to its failure response [1-3]. NDI is also an ideal material for studying the influence of microstructure on ductile fracture because it contains a readily identifiable second-phase particle population, embedded in a ductile metallic matrix, which serves as primary void nucleation sites. The material in this study met ASTM A536, 60-4018 specifications (minimum $60 \mathrm{ksi}$ (413 MPa) ultimate strength, minimum $40 \mathrm{ksi}$ (275 $\mathrm{MPa}$ ) yield strength, $18 \%$ elongation in 2 inch bar) and was purchased from DuraBar ${ }^{\circledR}$. A Fe-2.5\% Si alloy was used to model the matrix phase in NDI. The Fe-Si alloy was purchased from Carpenter Technology.

\section{Split Hopkinson Pressure Bar Compression Experiments}

As part of this study, split Hopkinson pressure bar (SHPB) compression experiments [4-5] were conducted to determine the strain-hardening response of NDI and its underlying FeSi matrix phase at strain rates of 2,000-4,000 s-1. The test uses a cylindrical projectile to impact a cylindrical incident bar which has been instrumented with strain gages. Figure 1 shows a schematic of the SHPB experiment. The impact sends a compressive stress wave down the incident bar, into the test sample and out through a transmitter bar with similar instrumentation. The signals from the two sets of instrumentation are compared and the net change is used to calculate the stress and strain caused by the stress wave.

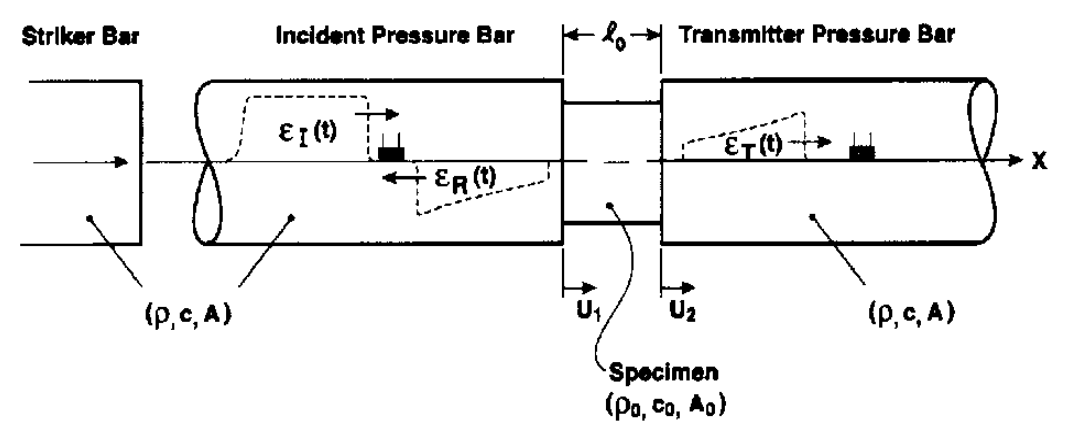

Figure 1. Schematic of split Hopkinson pressure bar (SHPB) compression experiment with emphasis on sample loading. 
Figure 2 shows the SHPB compression experiments performed at LLNL. It employs a modified Dynapak pneumatic press to supply the impulse to accelerate the cylindrical projectile with a maximum velocity of approximately $900 \mathrm{in} / \mathrm{s}(22.9 \mathrm{~m} / \mathrm{s})$. The standard compression bar set (incident and transmitter bars) used is made from high strength steel to provide for a wide range of material testing conditions. We normally use 0.2 in $(0.508$ $\mathrm{cm})$ height by 0.2 in $(0.508 \mathrm{~cm})$ diameter cylindrical test samples which fit the 0.56 in $(1.42$ $\mathrm{cm}$ ) steel compression bar set. Smaller sample sizes can be accommodated in cylindrical configurations as needed. The strain signals from the two bars during test are captured with a Nicolet Integra system at rates from $1 \mathrm{KHz}$ to $20 \mathrm{MHz}$ and evaluated using the commercial spreadsheet software to produce graphical representations of stress and strain.

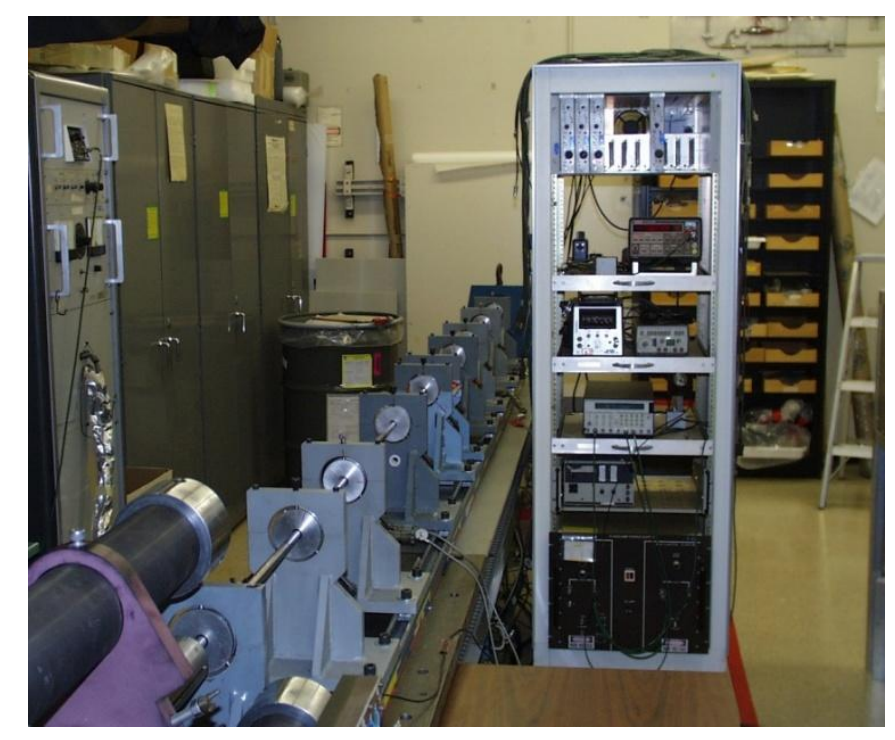

Figure 2. LLNL SHPB compression experiments.

SHPB experiments are essentially one dimensional uniaxial (stress) compression experiments. The one dimensional wave equation is used to develop equations relating the strain gage data to the specimen stress and strain rate in SHPB compression experiments. Starting with equation (1), the displacement gradient and rate can be defined at each incident bar (subscript 1) and transmitter bar (subscript 2):

$$
\begin{array}{ll}
u_{1}=f\left(x-c_{b} t\right)+g\left(x+c_{b} t\right) & u_{2}=h\left(x-c_{b} t\right) \\
\dot{u}_{1}=c_{b}\left(-f^{\prime}+g^{\prime}\right)=c_{b}\left(-\varepsilon_{i}+\varepsilon_{r}\right) & \dot{u}_{2}=-c_{b} h^{\prime}=-c_{b} \varepsilon_{t} \\
\frac{\partial u_{1}}{\partial x}=f^{\prime}+g^{\prime}=\varepsilon_{i}+\varepsilon_{r} & \frac{\partial u_{2}}{\partial x}=h^{\prime}
\end{array}
$$


where, $\varepsilon_{\mathrm{i}}$ is the incident strain, $\varepsilon_{\mathrm{r}}$ is the reflected strain, and $\varepsilon_{\mathrm{t}}$ is the transmitted strain. The strain data is taken directly from strain gages affixed to the incident and transmitter bar. The specimen strain rate and stress can now be defined:

$$
\begin{aligned}
& \dot{\varepsilon}_{\mathrm{s}}=\frac{1}{l_{0}}\left(\dot{u}_{1}-\dot{u}_{2}\right)=\frac{c_{b}}{l_{0}}\left(-\varepsilon_{i}+\varepsilon_{r}+\varepsilon_{\mathrm{t}}\right) \\
& \sigma_{s}=\frac{E A_{0}\left(\varepsilon_{i}+\varepsilon_{r}+\varepsilon_{\mathrm{t}}\right)}{2 A}
\end{aligned}
$$

where, $\dot{\varepsilon}_{S}$ is the specimen strain rate, $l_{0}$ is the instantaneous specimen length, $\sigma_{\mathrm{s}}$ is the specimen stress, $E$ is the Young's modulus of the incident and transmitter bars, $A_{0}$ is the initial cross-sectional area of the incident and transmitter bars, and $A$ is the instantaneous specimen cross-sectional area. Since there is a finite distance between incident and transmitter bar strain gages, $\varepsilon_{\mathrm{i}}, \varepsilon_{\mathrm{r}}$ and $\varepsilon_{\mathrm{t}}$ are out-of-phase. Strain gage data must be aligned before strain rate or stress is calculated, as part of the "three-wave" analysis to obtain the material strength response.

\section{Quasistatic Tension Fracture Experiments:Statistics at Different Length-Scales}

Quasistatic tension fracture experiments with two configurations of smooth round specimens were performed to probe variations of elongation-at-failure for differing size. Figure 3 shows the 0.5 in $(1.27 \mathrm{~cm})$ and 0.113 in $(0.287 \mathrm{~cm})$ diameter specimen configurations. Approximately twenty replicate tests were performed for each specimen configuration in order to obtain adequate statistics. Experiments were performed using the UC Davis 20 kip Instron 1331 system. Elongation was measured using a MTS 634.25 axial extensometer, shown in Figure 4. Experiments conformed to ASTM E8 standards.

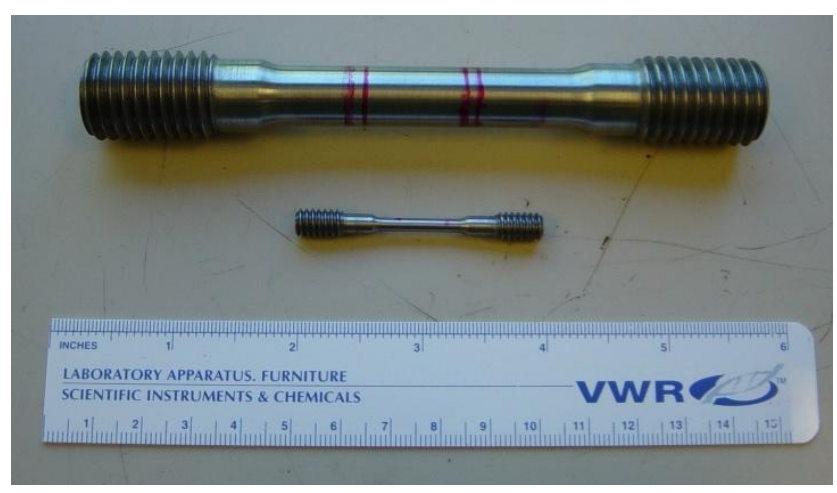

Figure 3. Smooth round NDI specimens- 0.5 in $(1.27 \mathrm{~cm})$ and 0.113 in $(0.287 \mathrm{~cm})$ diameter configurations. 


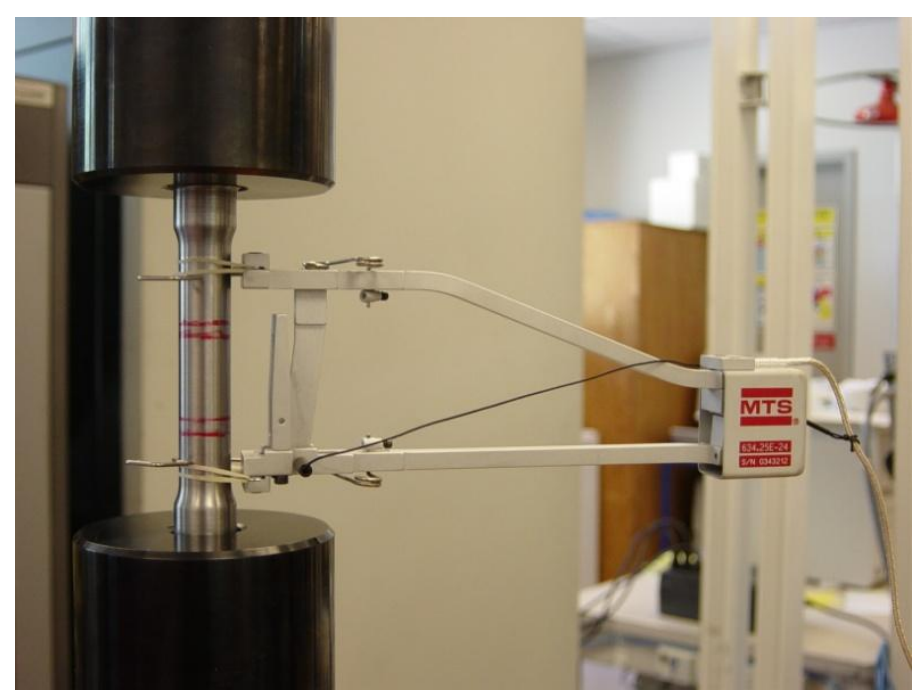

Figure 4. Measuring elongation in smooth round specimens with MTS 634.25 axial extensometer.

In order to relate one dimensional engineering stress and strain measurements to true stress and strain, as well as other convenient parameters, we use the following equations,

$$
\begin{aligned}
& s=\frac{P}{A_{0}} \\
& e=\frac{L-L_{0}}{L_{0}} \\
& \sigma=\frac{P}{A} \\
& \sigma=s(e+1) \\
& \varepsilon=\ln (e+1)=\ln \left(\frac{L}{L_{0}}\right)
\end{aligned}
$$

where $s$ is the engineering stress, $e$ is the engineering strain, $\sigma$ is the true stress, $\varepsilon$ is the true strain, $P$ is the load, $L_{0}$ and $L$ are the initial and current lengths, and $A_{0}$ and $A$ are the initial and current cross-sectional areas. Relationships in Equation (6) are applicable only until the onset of necking. After necking, deformation is no longer homogeneous, but localized, along the specimen and the isochoric assumption no longer applies. 


\section{Quasistatic Notched Round Bar (Tension) Fracture Experiments}

Quasistatic tension fracture experiments were performed with three configurations of notched round bar (NRB) specimens to explore the influence of stress triaxiality $\left(\sigma_{\mathrm{m}} / \sigma_{\text {eff }}\right)$ on strain-at-failure in NDI. Stress triaxiality was varied by changing the notch length, $2 \rho$, of the specimen to 0.0564 in $(0.143 \mathrm{~cm}), 0.113$ in $(0.287 \mathrm{~cm})$, and 0.226 in $(0.574 \mathrm{~cm})$, while keeping the diameter, $2 a$, fixed at 0.113 in $(0.287 \mathrm{~cm})$. Figure 5 shows these three notched round bar configurations and a schematic with the key notch geometric parameters, $2 a$ and $2 \rho$. Also, fifteen replicate tests were performed for each specimen configuration in order to probe strain-at-failure variations at different stress triaxialities. Experiments were performed using the LLNL $5 \mathrm{kN}$ MTS system. Strain-at-failure was measured using a custom (flexure) diametral extensometer located at the notch center.
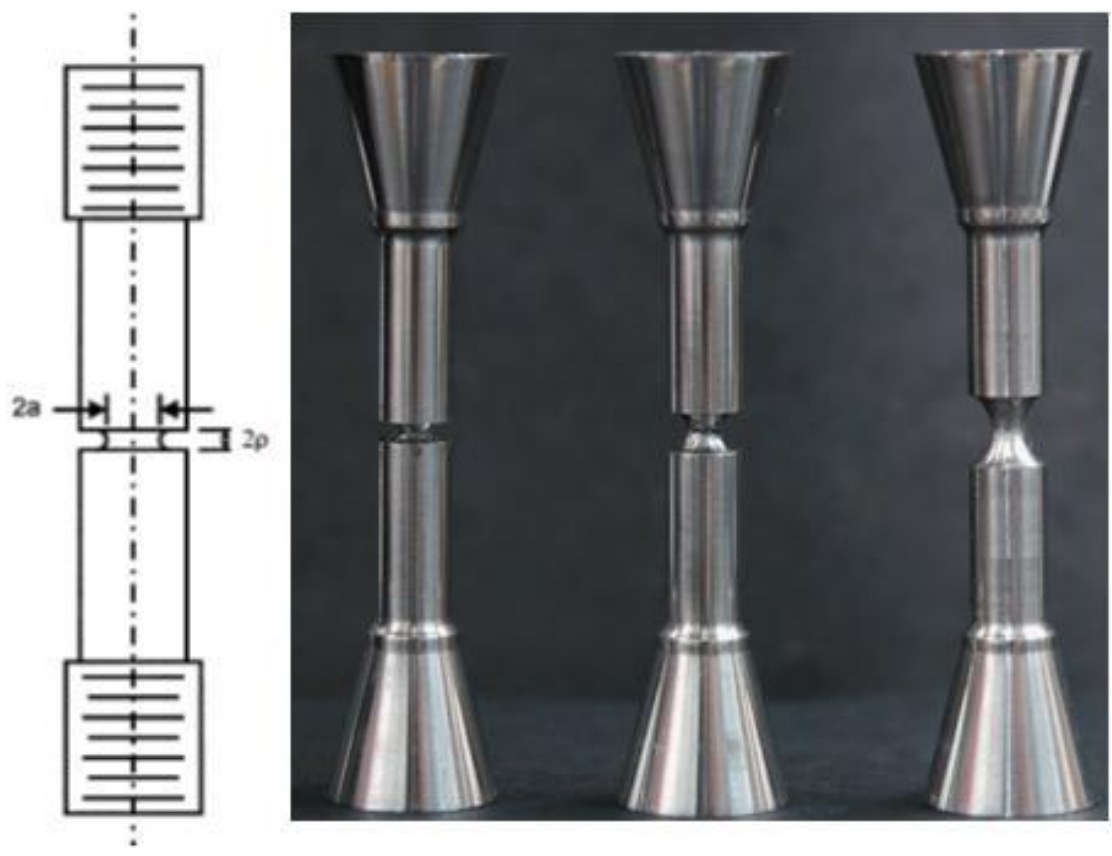

Figure 5. Notched round bar schematic and actual NDI specimens with fixed notch diameter of 0.113 in $(0.287 \mathrm{~cm})$ and notch lengths of $0.0564 \mathrm{in}(0.143 \mathrm{~cm})(\mathrm{left}), 0.113$ in $(0.287 \mathrm{~cm})$ (middle), and 0.226 in $(0.574 \mathrm{~cm})$ (right).

The (initial) stress triaxiality of the NRB specimens can be calculated using the Bridgman analysis [6], 


$$
\frac{\sigma_{m}}{\sigma_{e f f}}=\frac{1}{3}-\ln \left(\frac{a}{2 \rho}+1\right)
$$

where $\sigma_{\mathrm{m}}$ is the mean stress (positive in tension), $\sigma_{\text {eff }}$ is the effective stress (e.g., von Mises stress), $a$ is the notch radius, and $2 \rho$ is the notch length. Based on Equation (7), the initial stress triaxialities for the three specimen configurations are: $0.556(2 \rho=0.226 \mathrm{in}, 0.739$ ( $2 \rho=0.113 \mathrm{in})$, and $1.02(2 \rho=0.0564 \mathrm{in})$. The equivalent plastic strain (EPS), $\bar{\varepsilon}^{p l}$, was calculated based on direct diametric measurements using the relationship,

$$
\bar{\varepsilon}^{p l}=2 \ln \left(\frac{D_{o}}{D}\right)
$$

where $D_{0}$ and $D$ are the initial and current diameters. Equation (8) was used to calculate the EPS at failure for the different NRB specimen configurations.

\section{Results}

\section{NDI Strength at Different Strain-Rates}

Figure 6 shows the true stress versus EPS for NDI at quasistatic $(0.00068 / \mathrm{sec}$ average $)$ and higher-rates (2312/sec average) with a fit to the Johnson-Cook strength model [7]. This is a five-parameter empirical model that describes the yield strength as a function of plastic strain, plastic strain rate, and homologous temperature. It is expressed as,

$$
\sigma=\left(A+B\left(\bar{\varepsilon}^{p l}\right)^{n}\right)\left(1+C \ln \left(\frac{\dot{\bar{\varepsilon}}^{p l}}{\dot{\varepsilon}_{0}}\right)\right)\left(1-\left(\frac{T-T_{\text {room }}}{T_{\text {melt }}-T_{\text {room }}}\right)^{m}\right)
$$

where $A, B$ are the strain-hardening coefficients, $n$ is the strain hardening exponent, $\bar{\varepsilon}^{p l}$ is the current EPS, $C$ is the strain-rate hardening coefficient, $\dot{\varepsilon}_{0}$ is the reference strain rate (set to 2312 /sec, which is average rate from SHPB experiments), $\bar{\varepsilon}^{p l}$ is the current EPS rate, $\mathrm{T}_{\text {room }}$ is the room (reference) temperature, $\mathrm{T}_{\text {melt }}$ is the melt temperature, $m$ is the temperature exponent, and $T$ is the current temperature. Table 1 summarizes the JohnsonCook strength model parameter values, as well as the Young's Modulus which was calculated from a linear fit to quasi-static strength data up to a strain of 0.001 . Since all experiments were performed at room temperature, i.e., no temperature dependence was determined, the temperature exponent was set to 1 and the melt temperature set to large value $(100,000 \mathrm{~K})$. 


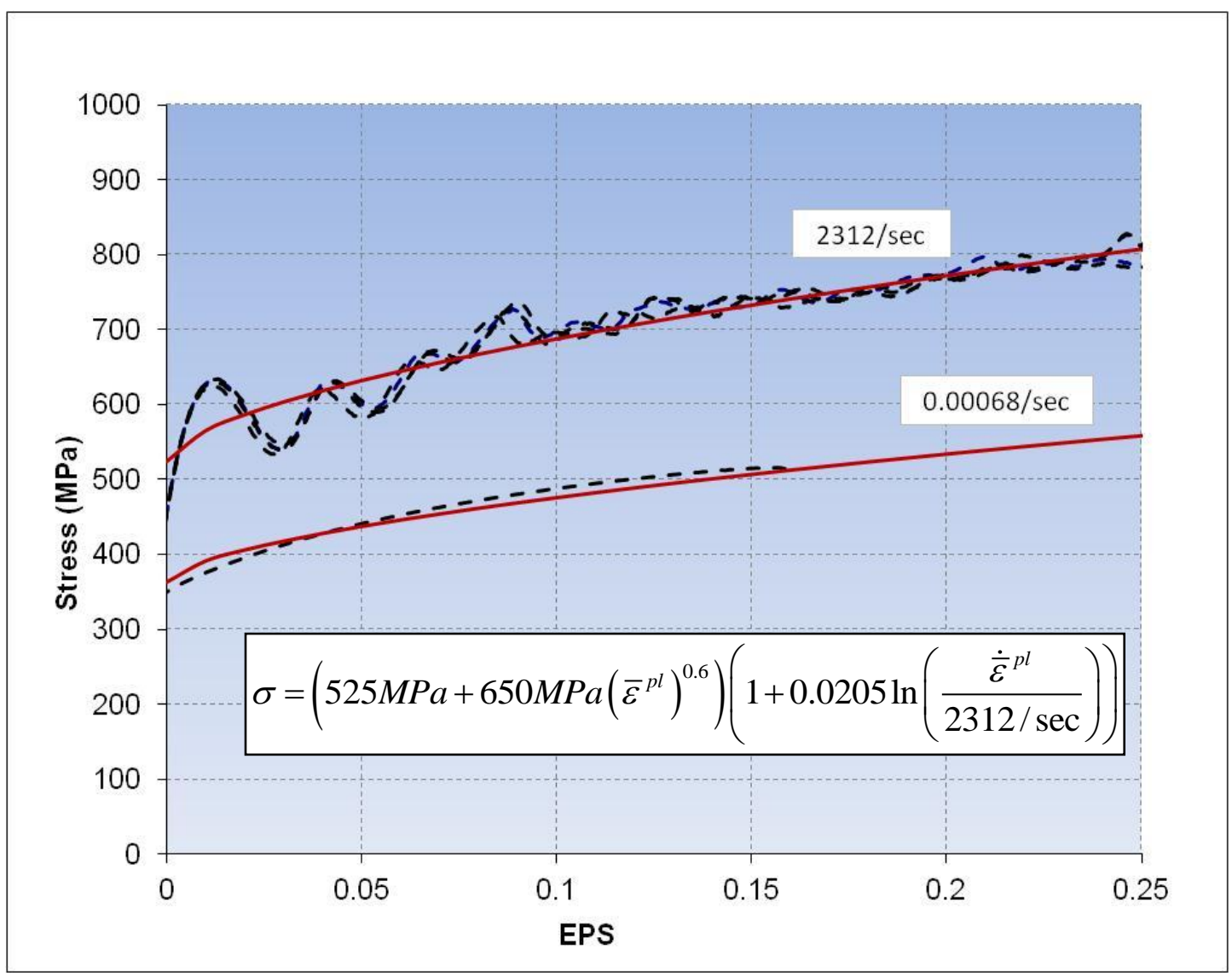

Figure 6. True stress versus EPS for NDI at quasistatic and higher-rates (black dashed lines). Johnson-Cook strength model fit also shown (red solid lines).

Table 1. Young's Modulus and Johnson-Cook strength model parameters for NDI

\begin{tabular}{|l|l|l|l|l|l|l|l|l|}
\hline $\begin{array}{l}\mathrm{E} \\
(\mathrm{GPa})\end{array}$ & $\begin{array}{l}A \\
(\mathrm{MPa})\end{array}$ & $\begin{array}{l}B \\
(\mathrm{MPa})\end{array}$ & $n$ & $C$ & $\begin{array}{l}\dot{\varepsilon}_{0} \\
(1 / \mathrm{s})\end{array}$ & $\begin{array}{l}T_{\text {room }} \\
(\mathrm{K})\end{array}$ & $\begin{array}{l}T_{\text {melt }} \\
(\mathrm{K})\end{array}$ & $m$ \\
\hline 151.1 & 525 & 650 & 0.6 & 0.0205 & 2312 & 298 & 100,000 & 1.0 \\
\hline
\end{tabular}




\section{Fe-Si Alloy Strength at Different Strain-Rates}

Figure 7 shows the true stress versus strain of the Fe-Si alloy at quasistatic $(0.00089 / \mathrm{sec}$ average) and higher-rates (2850/sec average) with Johnson-Cook strength model fit. Table 2 summarizes the Johnson-Cook strength model parameter values, as well as the Young's Modulus which was provided by the material vendor (Carpenter Technology). As with NDI, the temperature exponent was set to 1 and the melt temperature set to large value $(100,000 \mathrm{~K})$.

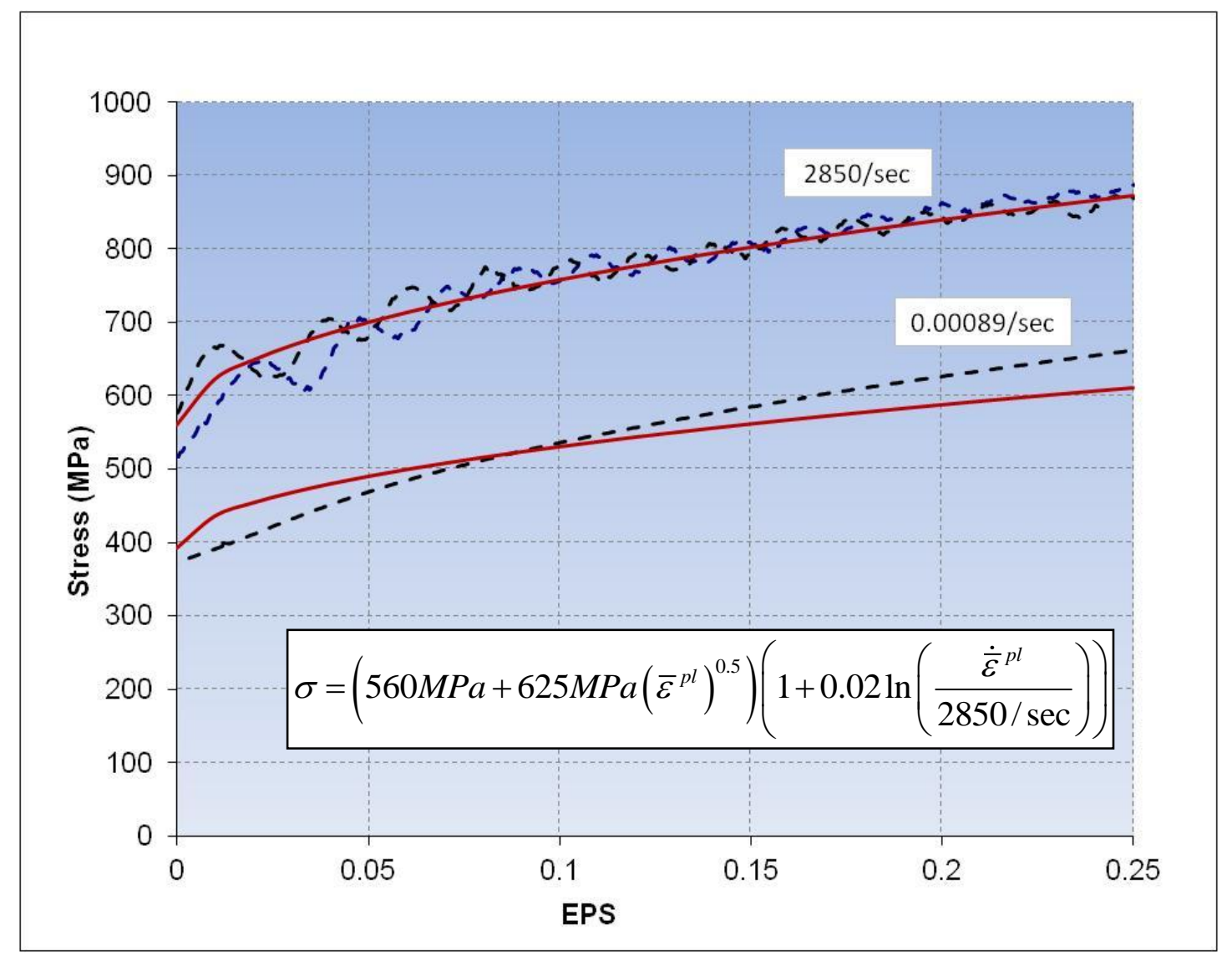

Figure 7. True stress versus EPS for Fe-Si alloy at quasistatic and higher-rates (black dashed lines). Johnson-Cook strength model fit also shown (red solid lines).

Table 2. Johnson-Cook strength model parameters for the Fe-Si alloy

\begin{tabular}{|l|l|l|l|l|l|l|l|l|}
\hline $\begin{array}{l}\mathrm{E} \\
(\mathrm{GPa})\end{array}$ & $\begin{array}{l}A \\
(\mathrm{MPa})\end{array}$ & $\begin{array}{l}B \\
(\mathrm{MPa})\end{array}$ & $n$ & $C$ & $\begin{array}{l}\dot{\varepsilon}_{0} \\
(1 / \mathrm{s})\end{array}$ & $\begin{array}{l}T_{\text {room }} \\
(\mathrm{K})\end{array}$ & $\begin{array}{l}T_{\text {melt }} \\
(\mathrm{K})\end{array}$ & $m$ \\
\hline 167 & 560 & 625 & 0.5 & 0.02 & 2850 & 298 & 100,000 & 1.0 \\
\hline
\end{tabular}




\section{NDI EPS-at-Failure for Different Stress Triaxialities}

Figure 8 shows the EPS at failure for the NRB experiments as a function of stress triaxiality with a fit to the Johnson-Cook fracture strain model [8]. This is a five-parameter empirical model that describes the fracture strain as a function of stress triaxiality, strain rate, and homologous temperature. It is expressed as,

$$
\bar{\varepsilon}^{f}=\left(D_{1}+D_{2} \exp \left(D_{3} \frac{\sigma_{m}}{\sigma_{\text {eff }}}\right)\right)\left(1+D_{4} \ln \left(\frac{\dot{\bar{\varepsilon}}^{p l}}{\dot{\varepsilon}_{0}}\right)\right)\left(1+D_{5}\left(\frac{T-T_{\text {room }}}{T_{\text {melt }}-T_{\text {room }}}\right)\right)
$$

where $D_{1}$ to $D_{5}$ are fitting constants and the other terms have been defined previously for the Johnson-Cook strength model. The first part of Equation (10) that describes the stress triaxiality is a generalization of the Hancock-McKenzie model [9]. As with [9], we assume that $\mathrm{D}_{3}$ is equal to -1.5 based on theoretical models of spherical void growth. Since we conducted all the experiments at a fixed strain rate (quasistatic) and fixed (ambient) temperature, we zero the strain-rate and temperature terms. It should be noted that the $\sigma_{\mathrm{m}}$ $=-p$ since pressure in the hydrocodes is defined to be positive in compression. So, the sign for $\mathrm{D}_{3}$ may need to be changed depending on how this failure model is implemented in the hydrocode. Table 3 summarizes the Johnson-Cook failure strain model parameter values. Data for the smooth bar specimens are not included in this section since only elongation-atfailure, not EPS-at-failure, was measured for those experiments.

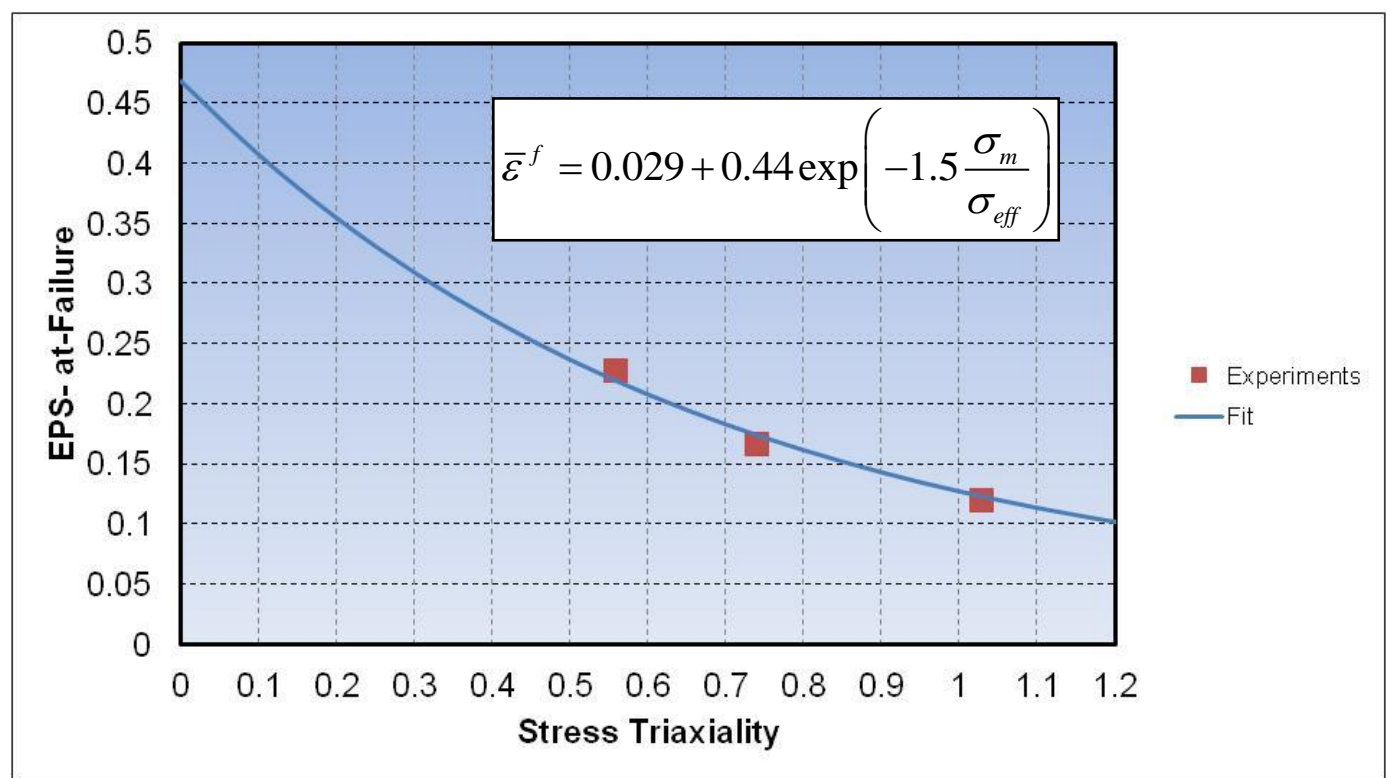

Figure 8. EPS at failure versus stress triaxiality data for NDI for NRB specimens (red boxes). Johnson-Cook failure strain model fit also shown (blue line). 
Table 3. Johnson-Cook failure strain model parameters for NDI. All parameters are unitless.

\begin{tabular}{|l|l|l|l|l|}
\hline $\mathrm{D}_{1}$ & $\mathrm{D}_{2}$ & $\mathrm{D}_{3}$ & $\mathrm{D}_{4}$ & $\mathrm{D}_{5}$ \\
\hline 0.029 & 0.44 & -1.5 & 0 & 0 \\
\hline
\end{tabular}

Table 4 shows the mean and standard deviation of EPS at failure for the different specimen geometries (stress triaxialities). The basis for failure statistics are the (fifteen) replicate tests performed in each configuration. The coefficient-of-variation (COV) is the ratio of the standard deviation (SD) to the mean value and is used here to normalize the SD values.

Table 4. EPS at failure statistics for different stress triaxialities (15 samples).

\begin{tabular}{|c|c|c|}
\hline$\sigma_{\mathrm{m}} / \sigma_{\mathrm{eff}}$ & $\begin{array}{c}\text { Mean and Standard } \\
\text { Deviation, EPS at } \\
\text { Failure }\end{array}$ & $\begin{array}{c}\text { Coefficient-of- } \\
\text { Variation }\end{array}$ \\
\hline 0.556 & $0.229 \pm 0.00933$ & 0.0407 \\
\hline 0.739 & $0.168 \pm 0.00528$ & 0.0314 \\
\hline 1.02 & $0.121 \pm 0.00445$ & 0.0367 \\
\hline
\end{tabular}

\section{NDI Elongation Statistics at Different Length-Scales}

Table 5 shows the elongation-at-failure $(e f)$ statistics for $1.27 \mathrm{~cm}$ and $0.287 \mathrm{~cm}$ diameter NDI (smooth, round bar) specimens. The mean and standard deviation, as well as the COV, are calculated for $e$.

Table 5. NDI elongation-at-failure statistics for $1.27 \mathrm{~cm}$ and $0.287 \mathrm{~cm}$ specimens.

\begin{tabular}{|c|c|c|c|}
\hline $\begin{array}{c}\text { Diameter } \\
(\mathrm{cm})\end{array}$ & $\begin{array}{c}\text { Number of } \\
\text { Specimens }\end{array}$ & $\begin{array}{c}e^{f} \\
\text { Mean and SD }\end{array}$ & $\begin{array}{c}e^{f} \\
\text { COV }\end{array}$ \\
\hline 0.287 & 21 & $0.1856 \pm 0.0173$ & 0.0930 \\
\hline 1.27 & 19 & $0.1896 \pm 0.0106$ & 0.0557 \\
\hline
\end{tabular}


Based on this data, we develop an exponential relationship for the $\operatorname{COV}_{f}$ as a function of length-scale similar to that in [10]:

$$
\operatorname{COV}_{f}(L)=\left[S_{f 1} \exp \left(S_{f 2} \frac{L}{L_{m}}\right)\right]
$$

where $L$ is the specimen length-scale (using specimen diameter) and $L_{m}$ is a microstructural length-scale. Based on [10], we use the graphite nodule nearest neighbor distance $(32.4 \mu \mathrm{m})$ as the microstructural length-scale. Fitted parameters $S_{f 1}$ and $S_{f 2}$ are 0.108 and -0.00169 , respectively. Relationships like Equation (11) enable the simulation of natural fragmentation events, which require material failure statistics.

\section{Conclusions}

The strength and fracture properties of nodular ductile iron (NDI), as well as its underlying ferritic matrix phase (Fe-Si alloy), were characterized in this study. The strength of NDI and the Fe-Si alloy were found to be dependent on equivalent plastic strain and plastic strain rate. Reasonable fits to NDI and Fe-Si alloy data were demonstrated using the JohnsonCook strength model. The equivalent plastic strain at failure in NDI was found to be dependent on stress triaxiality. A reasonable fit to experimental data was demonstrated using the Johnson-Cook failure strain model. The length-scale dependent elongation-atfailure statistics were fit to an exponential model. NDI strength and failure models, including failure statistics, will be used in continuum-scale simulations of explosivelydriven ring fragmentation. The Fe-Si alloy strength model will be used in mesoscale simulations of spall fracture in NDI, such as [10], where the NDI matrix phase is captured explicitly.

\section{Acknowledgements}

Special thanks to Professor Michael Hill of University of California, Davis, for providing quasistatic tensile testing facilities and David Urabe of Lawrence Livermore National Laboratory for helping conduct the NRB and SHPB testing. This work was performed under the auspices of the U.S. DOE by LLNL under Contract DE-AC52-07NA27344. This research was supported by the Joint DoD-DOE Munitions Technology Development Program. 


\section{References}

1. Clough, WR, Shank, ME; The Flow and Fracture of Nodular Cast Iron; Trans. Am. Mech. Engrs., 79 (1957) pp 1911-1920

2. Shi, J, Savas, MA, Smith, RW; Plastic deformation of a model material containing soft spheroidal inclusions: Spheroidal graphite cast iron; Journal of Materials Processing Technology, 133 (2003) pp 297-303

3. Liu, JH, Hao, XY, Li, GL, Liu, GS; Microvoid evaluation of ferrite ductile iron under strain; Materials Letters 56 (2002) pp 748-755

4. Hopkinson, B; Trans. R. Soc. London, 213A (1914) p 437

5. Kuhn, H, Medlin, D; ASM Handbook Volume 8: Mechanical Testing and Evaluation, ASM International (2000) pp 462-476

6. Bridgman, PW, Studies in Large Plastic Flow and Fracture, McGraw-Hill, New York (1952)

7. Johnson, GR, Cook, $\mathrm{WH}$, A constitutive model and data for metals subjected to large strains, high strain rates, and high temperatures, Proceedings of the $7^{\text {th }}$ International Symposium on Ballistics, The Hague, Netherlands (1983) pp 541-547

8. Johnson, GR, Cook, WH, Fracture Characteristics of Three Metals Subjected to Various Strains, Strain Rates, Temperatures and Pressures; Engineering Fracture Mechanics, 21:1 (1985) pp 31-48

9. Hancock, JW, Mackenzie, AC, On the mechanisms of ductile failure in high-strength steels subjected to multi-axial stress-states, Journal of the Mechanics and Physics of Solids, 24 (1976) pp 147-169

10. Springer, H. K., Mesoscale Modeling of Spall in a Heterogeneous Two-Phase Material, Ph.D. dissertation, UC Davis (2008) 